\title{
Ciência, poder e circulação de conhecimento no século XVIII: Ribeiro Sanches e o Brasil colonial
}

\author{
Gisele Cristina da Conceição ${ }^{1 *}$ \\ ${ }^{1}$ Universidade de São Paulo, São Paulo/SP - Brasil
}

\section{RESUMO}

O médico António Nunes Ribeiro Sanches (1699-1782) é amplamente conhecido pela sua participação ativa nos processos de reforma do ensino em Portugal durante o século XVIII. Suas conexóes com a Coroa e sua extensa rede de contatos favoreciam que o seu pensamento circulasse entre diversos grupos de indivíduos letrados. Sua atividade intelectual foi intensa a partir da segunda metade do século XVIII, em um período marcado pelo aumento do interesse da Coroa portuguesa em conhecer as potencialidades naturais de suas colonias ultramarinas. Foram muitas as políticas voltadas para processos de reconhecimento e construção de conhecimento sobre o Mundo Natural, e estes processos, em grande medida, impulsionaram a produção científica do período, da qual Ribeiro Sanches não esteve alheio. Nesse sentido, o objetivo deste artigo é verificar em que medida tais preocupaçôes também estiveram presentes em seus escritos.

Palavras-chave: António Nunes Ribeiro Sanches (1699-1782); Brasil Colônia; ciência e poder; Império Atlântico português; circulação de conhecimento.

\section{Science, power and the circulation of knowledge in the 18th century: Ribeiro Sanches and colonial Brazil}

\section{ABSTRACT}

The Portuguese physician António Nunes Ribeiro Sanches (1699-1782) is widely known for his active participation in educational reform processes in Portugal during the eighteenth century. His connections with the Crown, and his extensive network of contacts, facilitated

DOI: http://dx.doi.org/10.1590/2237-101X02004213.

Artigo recebido em 2 de outubro de 2018 e aceito para publicação em 8 de fevereiro de 2019.

* Pesquisadora da Universidade de Sáo Paulo/Faculdade de Filosofia, Letras e Ciências Humanas/Departamento de História, São Paulo/SP - Brasil. E-mail: giselecconceicao@gmail.com. ORCID: https://orcid. org/0000-0002-2251-805X. 
the circulation of his thought among several intellectual groups. His intellectual activity was intense from the second half of the eighteenth century onwards, in a period marked by the increased interest of the Portuguese Crown in knowing the natural potentialities of its overseas colonies. There were many policies aimed to the construction of knowledge about the Natural World. These processes largely promoted the scientific production of that period, in which Ribeiro Sanches took part. In this sense, the purpose of this article is to verify to what extent such concerns were also present in his works.

Keywords: António Nunes Ribeiro Sanches (1699-1782); Colonial Brazil; science and power; Portuguese Atlantic Empire; circulation of knowledge.

\section{Ciencia, poder y circulación de conocimiento en el siglo XVIII: Ribeiro Sanches y el Brasil colonial}

\section{RESUMEN}

El médico António Nunes Ribeiro Sanches (1699-1782) es ampliamente conocido por su participación activa en los procesos de reforma de la enseñanza en Portugal durante el siglo XVIII. Sus conexiones con la Corona, y su extensa red de contactos, favorecieron para que su pensamiento circulase entre diversos grupos de individuos letrados. Su actividad intelectual fue intensa a partir de la segunda mitad del siglo XVIII, en un periodo marcado por el aumento del interés de la Corona portuguesa en conocer las potencialidades naturales de sus colonias ultramarinas. Fueron muchas las políticas guiadas para procesos de reconocimiento y construcción de conocimiento sobre el Mundo Natural, y esos procesos, en gran medida, impulsaron la producción científica del periodo, de la cual Ribeiro Sanches no estuvo ajeno. En este sentido, el objetivo de este artículo es verificar, en qué medida, tales preocupaciones también estuvieron presentes en sus escritos.

Palabras clave: António Nunes Ribeiro Sanches (1699-1782); Brasil colonia; ciencia y poder; Imperio Atlántico portugués; circulación de conocimiento.

\section{Objetivos}

Este artigo tem como objetivo central demonstrar a circulação de conhecimento sobre a natureza das colônias portuguesas, através da análise de redes informais auto-organizadas por agentes localizados em diversos pontos do Império Português, e fora dele, mas que ti- 
nham interesses, posição social e econômica em comum ${ }^{1}$. Para isso, será feita análise da rede de contatos estabelecida por António Nunes Ribeiro Sanches, através de um texto escrito por ele em 1763, inédito até pouco tempo.

A análise levará em conta novas perspectivas teóricas que procuram compreender a circulação de conhecimento no Império Português, a partir da formação de redes informais e auto-organizadas por agentes que estavam envolvidos em disputas de poder, e em questóes políticas e econômicas, que, muitas vezes, acabavam por definir a validaçáo do conhecimento produzido.

\section{Introdução}

Podemos dizer que, ao longo de todo o século XVIII, é perceptível o esforço sistemático, principalmente sob os auspícios estatais, que visava promover a renovação das bases do conhecimento, tanto no Reino quanto nas colônias. Para esta análise, o período que se inicia em 1750 e vai até aproximadamente o final do século traz algumas das principais políticas de reformulação das bases educacionais e políticas implementadas pela Coroa, ligadas diretamente ao seu interesse em conhecer as potencialidades econômicas de suas colônias.

A análise está inserida neste contexto, no qual, em Portugal, houve considerável empenho da Coroa na tentativa de reformular as bases teórico-metodológicas do ensino ministrado na Universidade de Coimbra. Tais reformulaçóes processaram-se ao longo de todo o século XVIII, mas se intensificaram, em profundidade e velocidade, a partir da segunda metade do século. Para promover uma maior aproximação às estruturas pedagógicas e à forma como eram organizadas no resto da Europa, as Ciências Naturais ganharam paulatinamente mais espaço, principalmente com o trabalho de Domingos Vandelli (1735-1816) ${ }^{2}$ e sua equipe, tanto em Portugal quanto nos espaços coloniais. Além da preocupação em reconhecer o ambiente natural do próprio território português na Europa, as investigaçôes em território colonial, norteadas pela busca e exploração organizadas de recursos, elevaram

\footnotetext{
${ }^{1}$ POLÓNIA, Amélia; ANTUNES, Cátia. Seaports in the First Global Age: Portuguese agents, networks and interactions (1500-1800), Oporto: UPorto Editora, 2017a; PAQUETTE, Gabriel. Political economy, local knowledge, and the reform of the Portuguese Empire, c. 1750-1810. In: ASTIGARRAGA, Jesús; USOZ, Javier (eds.), L'économie politique et la sphère publique dans le débat des Lumières. Madrid: Casa de Velázquez, 2013, p. 245-258.

${ }^{2}$ Médico e filósofo natural italiano. A partir de 1764, quando contratado, Vandelli foi o principal idealizador de uma série de viagens pelo Reino e possessóes ultramarinas, todas elas ligando o caráter científico às intençôes de cunho econômico e político, tais como as de fazer um inventário dos recursos naturais que pudessem ser explorados no futuro. Vandelli tentou implementar algumas transformaçóes na Universidade de Coimbra para posicioná-la como um relevante centro de ensino e investigação na Europa. In: CONCEIÇÃO, Gisele C. Natureza ilustrada. Processos de construção de conhecimento filosófico-natural sobre o Brasil na segunda metade do Século XVIII. Tese (Doutorado), Faculdade de Letras da Universidade do Porto, 2017a.
} 
Portugal a membro de uma rede que contribuía para os estudos de História $\mathrm{Natural}^{3}$, num âmbito global.

Grande parte do processo reformista deste período consistiu também em uma completa troca de comando na Universidade, como consequência direta do processo mais amplo de expulsão dos Jesuítas dos domínios portugueses. ${ }^{4}$ Tradicionalmente, sob o comando dos padres da Companhia de Jesus, a Universidade de Coimbra disponibilizava apenas os cursos de Medicina, Leis e Teologia. 5 Essa troca de comando, ao excluir completamente os Jesuítas, promoveu a subordinação da Universidade diretamente aos interesses da Coroa que, na segunda metade do século XVIII, se encontrava aberta, ainda que de forma seletiva, a diversas ideias que circulavam na Europa, impulsionadas pelo pensamento iluminista. ${ }^{6}$ A partir desse impulso reformista, foram tomadas medidas reestruturantes, tanto de caráter organizacional quanto pedagógico. Um claro exemplo foi o das Faculdades de Filosofia, Matemática e Medicina, cujas disciplinas iam desde a História Natural à Física, Química e Geometria, e o início do processo de criação de um Jardim Botânico, paralelo à ênfase cada vez maior na formação de naturalistas.

Ainda no âmbito das reformas da universidade, o Marquês de Pombal (1750-1777) manteve-se em contato com algumas das ideias expostas por intelectuais, portugueses e estrangeiros, espalhados por toda a Europa, tais como António Nunes Ribeiro Sanches, Luís Antonio Verney, José Monteiro da Rocha (1734-1819) e Domingos Vandelli (1735-1816), mesmo que não as tenha adotado de forma integral. É nesse ponto que este artigo se aproxima de António Nunes Ribeiro Sanches, pois será a partir de um texto escrito por ele em 1763 que analisaremos os processos de construção e circulação de conhecimentos sobre as potencialidades naturais do Brasil.

Para isso, as discussóes foram divididas em quatro pontos fundamentais. O primeiro, trata, de modo geral, das dinâmicas de circulação de conhecimento no Império Português e do papel dos intelectuais portugueses na engrenagem desses processos. No segundo, Ribeiro Sanches se torna figura central de análise, com o objetivo de demonstrar o perfil desses intelectuais através de sua trajetória pessoal e profissional. O terceiro ponto centra-se no manuscrito escrito por ele em 1763, no qual é possível notarmos elementos descritivos sobre as

\footnotetext{
${ }^{3}$ PATACA, Ermelinda Moutinho. Terra, água e ar nas viagens cientificas portuguesas (1755-1808). Tese (Doutorado), Universidade Estadual de Campinas, Instituto de Geociências, Campinas, 2006; CARVALHO, Rómulo de. A História Natural em Portugal no século XVIII. Lisboa: Instituto de Cultura e Língua Portuguesa, 1987.

${ }^{4}$ VOGEL, Christine. Guerra aos jesuitas. A propaganda antijesuítica do Marquês de Pombal em Portugal e na Europa. Lisboa: Temas e Debates - Círculo de Leitores, p. 71-263, 2017.

5 PATACA, Ermelinda Moutinho. Terra, água e ar nas viagens científicas portuguesas (1755-1808), op. cit.

${ }^{6}$ BRIGOLA, João Carlos. Colecçôes, gabinetes e museus em Portugal no século XVIII. Lisboa: Fundação Calouste Gulbenkian, 2003; CAROLINO, Luis Miguel. State, science and empire in the Portuguese Atlantic (1770s-1820s). The Portuguese Journal of Social Science, [S.1.], v. 16, n. 1, sep. 2017; DOMINGUES, Ângela. Oficiais, cavalheiros e concorrentes: o "Brasil" nas viagens de circum-navegação do século das Luzes. Revista de Indias. v. LXXIII, n. 258, p. 365-398, 2013; RAMINELLI, Ronald. Viagens ultramarinas. Monarcas, vassalos e governo a distância. São Paulo: Alameda, 2008.
} 
potencialidades naturais do Brasil, principalmente aquelas úteis para a Medicina. Por fim, a análise retorna à questáo da circulação do conhecimento. A partir do manuscrito de Ribeiro Sanches e de outros, procuraremos demonstrar como operavam as dinâmicas de construção de redes informais auto-organizadas de agentes que faziam com que o conhecimento sobre as potencialidades naturais das colônias pudesse circular pelo Império Português e fora dele.

\section{Circulação de conhecimento no contexto do Império Português}

As disputas de poder entre os impérios marítimos europeus ao longo do século XVIII, principalmente em sua segunda metade, têm sido constante objeto de análise da historiografia e constituem um importante cerne para a compreensão das políticas da Coroa em relação aos espaços coloniais. A relação entre a conquista e a manutenção de territórios coloniais, rotas comerciais, frotas marítimas, interesses econômicos, estratégicos e políticos são intrínsecos à análise e ao entendimento do processo de disputa entre as potências europeias setecentistas. Nesse contexto, a ciência náo esteve alheia e passou a ter um expressivo caráter utilitarista, em que boa parte dos trabalhos deveriam ter como objetivo uma exploração organizada em prol de um maior conhecimento das rotas marítimas, dos territórios coloniais, dos instrumentos de medição e observação, e claro, das potencialidades naturais? parte da literatura científica produzida nesse período só pode ser compreendida mediante as relaçôes de poder estabelecidas entre os mais variados indivíduos e naçôes, que estavam conectados com a ideia de que conhecimento é poder. Pensar na literatura científica do século XVIII como proveniente de um cenário intelectual voltado exclusivamente para os estudos filosóficos acaba por excluir uma parcela significativa de produtores de trabalhos e as relaçóes deles com o seu demandante. ${ }^{8}$

Das relaçôes que envolviam a produçáo, a circulação e o reconhecimento dos trabalhos produzidos naquele período, podemos dizer que as relaçóes de poder, hierarquia ou a posição social relativas ao agente produtor eram determinantes, não apenas para as ideias expressas nos trabalhos, mas também para a recepção do trabalho no ambiente científico, ${ }^{9}$ ou seja, sua aceitação e o nível de importância que poderiam ganhar. A sociedade de corte e todas as relaçôes que, intrinsicamente, se teciam em seu seio, fizeram parte das relaçôes de poder que coexistiam com a própria formação, produção, aceitação e divulgação do conhecimen-

\footnotetext{
${ }^{7}$ DOMINGUES, Ângela. Oficiais, cavalheiros e concorrentes, op. cit., p. 371-372. Ângela Domingues estabelece comparação entre os relatos de Cook, Byron e Bougainville, para compreender a formação das literaturas de viagens deste período sobre o Brasil; DOMINGUES, Ângela. Para um melhor conhecimento dos domínios coloniais: a constituição de redes de informação no Império Português em finais do setecentos. História, Ciências, Saúde - Manguinhos, v. VIII (suplemento), p. 823-838, 2001.

${ }^{8}$ CONCEIÇÃO, Gisele C. Natureza ilustrada, op. cit.

${ }^{9}$ LIVINGSTONE, David N. Putting science in its place: geographies of science knowledge. Chicago, University of Chicago Press, 2013.
} 
to. Ao longo do tempo, essas relações foram se modificando, mas sem deixar de existir. Os trabalhos, que antes eram frequentemente dedicados a um mecenas ou importante figura ligada à Coroa, passaram a ser enviados e dedicados às Sociedades e Academias científicas ${ }^{10}$. O estabelecimento de relaçôes sociais e políticas fazia parte de um sistema no qual a ciência estava intimamente conectada ao poder.

Neste contexto, desde o início do século XVIII, no reinado de D. João V (1706-1750), podemos observar uma maior circulação de agentes, livros, conhecimento e correspondência entre os mais variados agentes, seja em Portugal, em países do norte da Europa ou nas colônias ${ }^{11}$. O Império Português estava conectado por vias marítimas ${ }^{12} \mathrm{e}$, através delas, não havia apenas circulação derivada do comércio, mas também uma intensa circulação de textos, fossem eles meras trocas de correspondência, ofícios, receitas comerciais, sermóes ou textos científicos, que circulavam através de redes de contatos auto-organizadas estabelecidas entre agentes que, no contexto do Império, ocupavam influentes posiçôes sociais e políticas.

Na primeira metade do século XVIII, boa parte do pensamento científico circulava através da troca de correspondência entre diplomatas, funcionários da Coroa e intelectuais. ${ }^{13}$ Os conteúdos dessas cartas eram os mais variados e, através delas, o conhecimento científco circulava e era validado. Tal cenário náo se modificou para a segunda metade do século XVIII, muito pelo contrário, se intensificou. $\mathrm{E}$ os trabalhos escritos a partir de meados do século passaram a tratar, em grande medida, das questôes políticas, econômicas e científicas dedicadas à averiguação das potencialidades naturais das colônias portuguesas, especialmente o Brasil ${ }^{14}$.

A maior movimentação de intelectuais no reinado de $\mathrm{D}$. João $\mathrm{V}$ também incentivou o início de um processo de rejuvenescimento da classe intelectual portuguesa, formando assim uma República de Letras. ${ }^{15}$ Foi nesse período que algumas mudanças foram iniciadas e proporcionaram uma maior abertura intelectual, seja com a circulação de indivíduos, livros e conhecimento, ou como a criação de espaços vocacionados para a produção científica, como

\footnotetext{
${ }^{10}$ BIAGIOLI, Mario. Galileu, cortesão. A prática da ciência na cultura do Absolutismo. Coordenação da coleção: Ana Simões e Henrique Leitão. Porto: Porto Editora, 2003.

${ }^{11}$ FURTADO, Júnia Ferreira. Oráculos da Geografia iluminista: Dom Luís da Cunha e Jean-Baptiste Bourguignon D’Anville na construção da cartografia do Brasil. Belo Horizonte: UFMG, 2012.

${ }^{12}$ ALENCASTRO, Luiz Felipe de. A rede económica do Mundo Atlântico português. In: BETHENCOURT, Francisco; CURTO, Diogo Ramada. A expansão marítima portuguesa, 1400-1800. Lisboa: Ediçóes 70, 2010. ${ }^{13}$ FURTADO, Júnia Ferreira. Oráculos da Geografia iluminista, op. cit.; ALENCASTRO, Luiz Felipe de. A rede económica do Mundo Atlântico português, op. cit.

${ }^{14}$ CONCEIÇÃOO, Gisele C. Evidências da circulação de conhecimento filosófico-natural sobre o Brasil em um manuscrito de 1763 de António Nunes Ribeiro Sanches. História, Ciências, Saúde-Manguinhos, Rio de Janeiro, v. 24, p. 519-533, 2017; CONCEIÇÃO, Gisele C. Science and power relations: circulation of agents and knowledge between Portugal and Brazil in the eighteenth century. In: POLÓNIA, Amélia; BRACHT Fabiano; CONCEIÇÃO, Gisele C.; PALMA, Monique (orgs.). Cross-cultural exchange and the circulation of knowledge in the First Global Age. 1. ed. Porto: Ediçôes Afrontamento/CITCEM, 2018, v. 1, p. 15-35.

${ }^{15}$ FURTADO, Júnia Ferreira. Oráculos da Geografia iluminista, op. cit.
} 
ocorreu com a formação da Academia Real da História Portuguesa. Júnia Ferreira Furtado (2012) discutiu amplamente esse processo através da obra, correspondência e carreira diplomática de D. Luís da Cunha (1662-1749). Homem de letras e de confiança do Rei, ultrapassou os limites da carreira diplomática e teve papel fundamental no processo de circulação de conhecimento entre Portugal e os países do norte da Europa. Uma de suas principais funçóes foi a de se encarregar de selecionar e comprar os mais modernos livros do período e enviar para Portugal para que pudessem compor a Biblioteca Real. Alguns desses exemplares estavam mesmo incluídos na lista de livros proibidos pela Inquisição. ${ }^{16}$

Essa mobilidade de homens e ideias foi, entre outros, fator preponderante para que houvesse certa dinamização da produção de conhecimento, não apenas em Portugal, mas em toda a Europa. A importância de se fazer um périplo pelas principais universidades da Europa sempre existiu, ${ }^{17}$ e, no caso português, muitos foram os intelectuais que se empenharam nessa tarefa. De fato, essa circulação de agentes pelas instituiçóes científicas acontecia desde a Idade Média ${ }^{18}$ e se intensificou como um curso natural da formação e produção de ciência na Europa. Neste cenário, podemos destacar figuras como o Conde de Ericeira, Luís António Verney (1713-1792), Martinho de Albuquerque e António Nunes Ribeiro Sanches (1699-1783), que desenvolveram propostas inovadoras para a reformulação da educação e da ciência em Portugal. Figuram como exemplos de intelectuais portugueses que saíram do Reino e fizeram o périplo europeu ainda na primeira metade do século XVIII.

Esses agentes fizeram o grand tour pelas principais instituições de ensino da Europa e arregimentaram os mais modernos pensamentos científicos em torno da situação político-científica portuguesa. Os indivíduos que empreendiam o grand tour eram homens da elite portuguesa que deixavam o seu país para estudar ou trabalhar e buscavam novos conhecimentos em Universidades espalhadas pela Europa. ${ }^{19} \mathrm{Na}$ segunda metade do século XVIII, esses agentes, muitas vezes, voltavam imbuídos dos ideais reformadores iluministas que visavam à reestruturação das bases de pensamento científico em todas as áreas de conhecimento. Parte fundamental da ação desses indivíduos se deu através do estabelecimento de extensas redes de comunicação, que tiveram grande importância nos processos de transformação das políticas estatais para a ciência e o ensino em Portugal.

\footnotetext{
${ }^{16}$ Idem; DENIPOTI, Cláudio; LIMA E FONSECA, Thais Nivea de. Censura e mercê - os pedidos de leitura e posse de livros proibidos em Portugal no século XVIII. Revista Brasileira de História da Ciência, Rio de Janeiro, v. 4, n. 2, p. 139-154, 2011.

${ }^{17}$ GRANT, Edward. Os fundamentos da Ciência Moderna na Idade Média. Porto: Porto Editora, 2002.

${ }^{18}$ GRANT, Edward. Os fundamentos da Ciência Moderna na Idade Média, op. cit.

${ }^{19}$ CARNEIRO, Ana; SIMÓES, Ana; DIOGO, Maria Paula. Enlightenment science in Portugal: the estrangeirados and their communication networks. Social Studies of Science, 30/4, p. 591-619, 2000; CONCEIÇÃO, Gisele C. Science and power relations, 2018, op. cit.
} 
Da circulação de indivíduos e trabalhos entre Portugal e os demais países europeus e entre os espaços coloniais e a Europa, construiu-se uma extensa rede auto-organizada ${ }^{20} \mathrm{de}$ troca de informaçóes. Dentro dessas redes, circulou uma variada tipologia de temas, especialmente aqueles relativos ao ambiente natural das colônias. Nesse caso, encontram-se Ribeiro Sanches e seus interlocutores.

\section{Um médico a serviço da Coroa e da ciência}

António Nunes Ribeiro Sanches nasceu em 1699, em Penamacor, uma vila no centro de Portugal. Cristáo-novo, deixou o país ainda jovem e nunca mais regressou. Seus estudos foram iniciados na Universidade de Coimbra, em princípios do século XVIII, transferindo-se mais tarde para a Universidade de Salamanca - Espanha, onde recebeu o título de doutor em Medicina, em 1724. Sua vida e sua obra foram exaustivamente estudadas pelo historiador português Maximiano Lemos, sendo ainda hoje objeto de estudos, dada a importância do impacto de seus pensamentos e obras em algumas das principais reformas implementadas na educaçáo e na saúde, principalmente a partir da segunda metade do século XVIII.

A peregrinação de Ribeiro Sanches por grandes centros intelectuais da Europa e as influências absorvidas neste processo são identificáveis em seus trabalhos, e influenciaram as políticas científicas e educacionais em Portugal. Em seu périplo europeu, o médico português passou por Génova, Montpellier, Bordéus e Londres, onde travou contato com intelectuais locais, pôde apreender novas vertentes científicas e exercer a Medicina. Depois, partiu para a Holanda, onde conviveu e foi discípulo do célebre médico - Hermann Boerhaave. Mais tarde, em 1731, recomendado pelo próprio Boerhaave, Ribeiro Sanches partiu para a Rússia para exercer a função de médico do exército, ganhando fama e prestígio, o que o levou a ser nomeado médico pessoal da czarina Ana Ivanovna. Em 1739, foi nomeado membro da Academia de Ciências de Sáo Petersburgo e, no mesmo ano, recebeu a mesma nomeação para a Academia de Ciências de Paris. ${ }^{21} \mathrm{Na}$ lista de sócios da Academia das Ciências de Lisboa, consta a nomeação de Ribeiro Sanches em 22 de maio de 1780.

Por motivos conturbados, Ribeiro Sanches acabou sendo envolvido em intrigas de Estado, e, por isso, partiu de São Petersburgo para Paris (onde viveu até a sua morte, em 1783) e ali teceu importantes conexôes com a mais alta intelectualidade francesa, absorvendo os

${ }^{20}$ Para uma perspectiva semelhante, ver: POLÓNIA, Amélia e ANTUNES, Cátia. Mechanisms of Global Empire building. Oporto: CITCEM, 2017; POLÓNIA, Amélia e ANTUNES, Cátia. Seaports in the First Global Age: Portuguese agents, networks and interactions (1500-1800). Oporto: UPorto Editora, 2017a.

${ }^{21}$ FURTADO, Júnia Ferreira. Oráculos da Geografia iluminista, op. cit.; RAMOS-JUNIOR, Nelson de Campos. Mediador das Luzes: concepçôes de progresso e ciência em António Nunes Ribeiro Sanches (1699-1783). Dissertação (Mestrado), Faculdade de Filosofia, Letras e Ciências Humanas - Universidade de São Paulo, São Paulo, 2013; LEMOS, Maximiano. Ribeiro Sanches: a sua vida e a sua obra. Porto: Eduardo Tavares Martins, 1911. 
pensamentos iluministas e participando ativamente na construção de um novo ambiente científico em Portugal. Nesse período, foi extenso o número de textos escritos por Ribeiro Sanches, tendo sua fama intelectual ganhado ainda mais destaque. Suas principais obras abordaram temas relacionados com a Medicina, a Educação e a História Natural.

Ainda em Portugal, Ribeiro Sanches escreveu o Discurso sobre as águas de Penha Garcia em 1726. A convite de Diderot, escreveu o verbete sobre doenças venéreas para a Encyclopedie. Nos anos seguintes, o médico português publicou suas principais obras para o âmbito político e científico português: 1756 - Tratado da conservação da saúde dos povos; 1760 Cartas sobre a educação da mocidade (sendo uma das mais importantes e influentes para o período); 1763 - Método para aprender e estudar a Medicina. E, por fim, em 1779, Mémoire sur les bains de vapeur en Russie. ${ }^{22}$

Ribeiro Sanches tinha uma influente rede de contatos e, através dela, expunha seus pensamentos e seus trabalhos. Nela, segundo Júnia Ferreira Furtado (2012), estavam Dom Luís da Cunha (1662-1749), Denis Diderot (1713-1784), Georges-Louis Leclerc, conde de Buffon (1707-1788), Leonhard Paul Euler (1707-1783), Herman Boerhaave (1668-1738), D’Alembert (1717-1783), Sebastião José de Carvalho e Melo (1699-1782); Joseph-Nicolas Delisle (1688-1768), Étienne-Maurice Falconet (1716-1791), além de outros, como o seu sobrinho, o médico José Henriques Ferreira, que será coadjuvante nesta análise.

Assim que chegou a Paris, Ribeiro Sanches estabeleceu uma importante ligação com Dom Luís da Cunha. As ideias do diplomata e do médico confluíam em vários pontos, tendo se estabelecido uma parceria. Tal conexão de pensamentos pode ser verificada no texto escrito em 1730 por Dom Luís da Cunha - Método com que se deve estudar e ensinar a filosofia e medicina moderna, para o qual recebeu colaboração de Ribeiro de Sanches. Segundo Júnia Ferreira Furtado, nesse texto de Dom Luís da Cunha, é possível notar alguns elementos que depois foram implementados pelo Marquês de Pombal em suas reformas (1750-1777). ${ }^{23}$

Mesmo que nunca tenha retornado a Portugal, Ribeiro Sanches foi figura de importante destaque na composição de muitas das políticas científicas e educacionais implementadas ao longo do século XVIII. Conectando-se com figuras centrais do Estado português, como Dom Luís da Cunha e o Marquês de Pombal, suas ideias (mesmo que não na totalidade) puderam ser incorporadas nas reformas pombalinas. Ribeiro Sanches participou ativamente na construção das bases políticas e científicas para uma restruturação da Universidade de Coimbra, em particular nos processos de desenvolvimento e reforma do pensamento médi-

\footnotetext{
${ }^{22}$ LEMOS, Maximiano. Ribeiro Sanches, op. cit. Para compreender os processos de construção de saber médico no pensamento de Ribeiro Sanches, ler: ABREU, Jean Luiz Neves. Higiene e conservação da saúde no pensamento médico luso-brasileiro do século XVIII. Asclepio (Madrid), v. 62, p. 225-250, 2010; ABREU, Laurinda. Public health and social reforms in Portugal (1780-1805). New Castle, Cambridge Scholars Publishing, 2017.

${ }^{23}$ FURTADO, Júnia Ferreira. Oráculos da Geografia iluminista, op. cit., p. 142.
} 
co e educacional. ${ }^{24}$ Pleiteava junto à Coroa portuguesa o aumento dos incentivos para que os intelectuais fizessem o périplo europeu. Suas ideias, seus trabalhos, suas críticas foram abundantes e circularam por todo o Império e fora dele. Sua obra, já há muito discutida e analisada pela historiografia, é vasta e variada. São estudos, textos e cartas trocadas entre seus colegas de profissão e indivíduos ligados à Coroa. Ideias postas em papel, publicadas ou não, os textos de Ribeiro Sanches dissertavam sobre muitos aspectos da produção de conhecimento científico de seu período e circularam entre sua extensa rede de contatos.

Algumas das políticas reformistas implementadas pelo Marquês de Pombal diziam respeito às colônias e aos estudos filosófico-naturais, e parte dessa correspondência também devia tratar desse tema, afinal, ao longo daquele período, os intelectuais, estando em Portugal ou em países estrangeiros, estavam preocupados com a situação das colônias e com o reconhecimento de suas potencialidades, e claro, atentos à questão do reconhecimento e estabelecimento das fronteiras, principalmente com Espanha. ${ }^{25}$ Nesse sentido, sabe-se que o médico escreveu algumas páginas, em momentos distintos, sobre as colônias e suas potencialidades naturais que pudessem ser utilizadas pela Coroa. É nesse aspecto que o nosso interesse repousa.

Os textos conhecidos que abordaram esse tema são o Discurso sobre as colónias, sobre a América portuguesa e sobre a agricultura, de 1763; as Consideraçôes sobre o governo do Brasil desde o seu estabelecimento até o presente tempo, de 1777; Sobre as lavouras e fábricas de tabaco do Brasil, de 1778; e Dos efeitos do descobrimento da América e conquistas, e se as colónias devem ser regidas pelas mesmas leis que o centro do Reino de que dependem, ${ }^{26}$ cuja data é desconhecida. ${ }^{27}$ Além desses textos específicos, Ribeiro Sanches fez menção em suas principais obras à situação das colônias e sua exploração organizada para que os domínios naturais pudessem ser devidamente utilizados para a Medicina e o comércio, como ocorre nas Cartas sobre a educação da mocidade, de 1760; e no Método para aprender e estudar a Medicina, de 1763.

Dentro desse complexo de trabalhos escritos por Ribeiro Sanches, alguns diziam respeito às possessôes ultramarinas, sua natureza, suas potencialidades naturais úteis para o comércio, para a Medicina e para a História Natural, encontramos um manuscrito inédito sobre as colônias, concretamente o Brasil, datado de 1763, Apontamentos para descobrir na America portugueza aquellas producçoens naturaes que podem enriquecer a Medecina, e o commercio. ${ }^{28}$

Segundo historiadores como Maximiano Lemos (1911), Victor de Sá (1980) e Innocencio Francisco da Silva (1867), sobre esse manuscrito, que se acreditava perdido, sabe-se que foi planejado por Ribeiro Sanches e, possivelmente, enviado a D. Vicente de Sousa Coutinho

\footnotetext{
${ }^{24}$ Idem; RAMOS-JUNIOR, Nelson de Campos. Mediador das Luzes, op. cit.

${ }^{25}$ PATACA, Ermelinda Moutinho. Terra, água e ar nas viagens cientificas portuguesas (1755-1808), op. cit.; BRIGOLA, João Carlos. Colecçōes, gabinetes e museus em Portugal no século XVIII, op. cit.

${ }^{26}$ Boa parte destes textos encontra-se microfilmada e disponível para consulta na Biblioteca Nacional de Portugal. Outros já estão publicados. A maioria foi listada e analisada por Maximiano Lemos.

${ }^{27}$ LEMOS, Maximiano. Ribeiro Sanches, op. cit.

${ }^{28}$ Biblioteca Nacional de Portugal (BNP), Lisboa: Seção dos Reservados, COD. 6941//4.
} 
$(1726-1792)^{29}$ e/ou ao Marquês de Pombal. Ribeiro Sanches, que desejava servir à Coroa, teria julgado útil que se escrevessem algumas páginas sobre o ambiente natural das colônias, especialmente o Brasil, mas deixando transparecer que a Coroa também deveria voltar suas atenções para África. ${ }^{30}$ Esse desejo ficou expresso em uma carta, também de 1763, que, possivelmente, teria sido enviada para Sousa Coutinho e/ou ao Marquês de Pombal. Transcrita por Innocencio Francisco da Silva, nela, Ribeiro Sanches comentou: "[...] O amor que conservo para a pátria, e o desejo de servir e agradar a v. exa ${ }^{\mathrm{a}}$, me incitaram prometer-lhe que escreveria sobre a agricultura, sobre o commercio, e sobre a população da America portuguesa". ${ }^{31}$ Contudo, pretendia fazê-lo em comparação com outras possessóes atlânticas, nomeadamente inglesas, holandesas e francesas, o que se lhe mostrou como uma tarefa árdua: "Comecei logo a dispor o que tinha apontado pela leitura nesta matéria, a combinar as differencas que se acham entre as nossas colônias, e as das mais nações [...] e então é que me apercebi da dificuldade de executar o que na verdade prometti com facilidade". ${ }^{32}$

O conteúdo do texto de Ribeiro Sanches, o enredo em torno dos possíveis destinatários do manuscrito e sua intenção em entrar nos círculos de discussões em torno da políticas de reconhecimento do ambiente natural das colônias portuguesas são importantes para a compreensão de dois fatores: primeiro, a multímoda rede de contatos e trocas de correspondência de Ribeiro Sanches, pois envolvia não somente a circulação de ideias entre ele e o seu interlocutor, mas também a circulação delas para o Brasil, como veremos, ele também estabeleceu contatos com agentes que estavam em território colonial. Segundo, as relaçóes de poder e influência que permeavam a sociedade de corte em Portugal promoviam uma intensa troca de informaçôes que impulsionavam a produção de conhecimento sobre as colônias. Além disso, o caso de Ribeiro Sanches nos serve como exemplo para entendermos como o conhecimento pôde circular dentro e fora do Império e nos abre uma via de interpretação dos jogos de poder que cingiam a produção de conhecimento e a circulação e sua validação nos meios científicos e políticos do Império Português.

\section{Potencialidades naturais do Brasil}

As políticas de expansão territorial a partir de 1750, para o interior do Brasil, principalmente quando pensamos nas regióes limítrofes com os territórios espanhóis, foram fomen-

${ }^{29}$ D. Vicente de Sousa Coutinho foi um importante e influente embaixador português em Paris.

${ }^{30}$ CONCEIÇÃO, Gisele C. Evidências da circulação de conhecimento filosófico-natural sobre o Brasil em um manuscrito de 1763 de António Nunes Ribeiro Sanches, op. cit., p. 521-522.

${ }^{31}$ SILVA, Innocencio Francisco da. Diccionario Bibliographico Portuguez - Estudos de Innocencio Francisco da Silva Applicaveis a Portugal e ao Brasil. Tomo VIII (10 suplemento), Lisboa, na Imprensa Nacional, MDCCCLXVII.

${ }^{32}$ BNP, Seção dos reservados, COD. 6941//4. 
tadas pela Coroa de maneira a adquirir um maior conhecimento e domínio desses espaços geográficos, tendo em vista a própria expansão da agricultura e do comércio, setores básicos da exploração colonial. Em parte, foi nesse contexto que os estudos filosófico-naturais sobre o Brasil foram pensados e postos em prática. Não apenas a Coroa portuguesa se empenhou nesse processo. De igual modo, holandeses, franceses, ingleses e espanhóis empreenderam continuadas viagens e estudos de reconhecimento territorial e viagens científicas por suas colônias. ${ }^{33}$ Tais aspectos, por sua vez, podem ser pensados em associação com a articulação de conhecimentos e incentivos no campo das práticas científicas. ${ }^{34}$

Motivado por interesses políticos, econômicos e acadêmicos, é notável o aumento do interesse da Coroa portuguesa em ampliar seus conhecimentos sobre as colônias. Esse interesse traduziu-se em um significativo aumento do número de agentes, inseridos em contextos coloniais ou não, que buscavam produzir trabalhos específicos sobre a geografia, as populaçôes indígenas, ou escrever sobre o ambiente natural das colônias e apresentar mecanismos que deveriam ser utilizados pela Coroa para potencializar o conhecimento e a utilização dos recursos naturais para o comércio e para as ciências. ${ }^{35}$ Muitos foram os agentes envolvidos nos contextos coloniais, mas náo só, que se debruçaram sobre este tema, e muitos foram os documentos produzidos por eles. A documentação, em grande parte manuscrita, pode ser analisada no sentido de compreendermos como os processos de reconhecimento e construção de conhecimento sobre os recursos naturais das colônias ocorreram e quais foram os possíveis usos dados pela Coroa.

Nesse período, o cenário político-científico em Portugal estava totalmente voltado para a construção de bases que pudessem organizar a ciência no país, de acordo com o pensamento iluminista. A classe letrada criticava a Coroa e apresentava possíveis soluçóes para o enriquecimento intelectual do país. Os Apontamentos, de 1763, de Ribeiro Sanches, assim como outros, inclui perspectiva.

Dividido em quatro partes, o texto versa, ao longo de 25 páginas manuscritas, sobre alguns dos pontos fundamentais que foram, mais tarde, adotados pelo Marquês de Pombal em suas reformas, não apenas da Universidade, mas nas políticas de Estado, como, por exemplo, o incentivo à averiguação e implantação de culturas agrícolas, assim como a verificação de plantas nativas das colônias que pudessem servir para a Medicina.

Logo na introdução de seu texto, Ribeiro Sanches afirmou que:

${ }^{33}$ DOMINGUES, Ângela. Oficiais, cavalheiros e concorrentes, op. cit., p. 369.

${ }^{4}$ SANJAD, Nelson. Ciência e poder imperial no Grão-Pará: Da expansão a desconstrução (1750-1840). In: KURY, Lorelai; GESTEIRA, Heloisa (orgs.). Ensaios de história das ciências no Brasil: das Luzes à nação Independente. Rio de Janeiro: EdUERJ, 2012, p. 225.

${ }^{35}$ CONCEIÇÃO, Gisele C. Natureza ilustrada: estudos sobre Filosofia Natural no Brasil ao longo século XVIII. In: POLÓNIA, Amélia; BRACHT, Fabiano; CONCEIÇÃO, Gisele C.; PALMA, Monique (orgs.). História e ciência: ciência e poder na primeira Idade Global. 1. ed. Porto: Universidade do Porto. Faculdade de Letras, v. 1, 2016, p. 142-179. 
Se a America Portugueza estivesse estabelecida desde a sua primeira origem na agricultura unniversal e no commercio, teríamos hoje muitos conhecimentos das suas producçóes que totalmente ignoramos. Parece que até agora não se avaliou aquelle domínio se não para dominar os gentios, e tirar ouro das suas minas; não considerando por riqueza aquella que provem da agricultura. ${ }^{36}$

Nesse contexto, segundo Ermelinda Pataca, ${ }^{37}$ já no final do século XVIII, uma das instruçóes de Domingos Vandelli, coordenador das Viagens Filosóficas na Universidade de Coimbra pós-reforma, foi o levantamento de dados pelos naturalistas, no que concerne à constituição química dos solos propícios para o cultivo de vegetais. Um incentivo claro à agricultura nos espaços coloniais. A autora também citou Ribeiro Sanches e evidenciou a preocupação do médico em relação a esse tema no trabalho, também de 1763, Methodo para aprender e estudar a medicina... Pataca ressaltou a crítica de Ribeiro Sanches quanto às políticas de fomento a respeito dos estreitamentos de relaçóes entre a Metrópole e suas possessóes no ultramar. Ribeiro Sanches já havia sugerido no Methodo para aprender e estudar a medicina... que a Coroa deveria focar as energias em reconhecer, nas colônias, as matérias naturais que pudessem servir não somente para a agricultura e comércio, mas também para a prática da Medicina, argumento reforçado também nos Apontamentos de 1763.

Além do possível envio dos Apontamentos, de 1763, sabe-se que houve circulação de cartas entre Ribeiro Sanches e Sebastião José de Carvalho e Melo. O conteúdo dessas cartas é, de certa forma, uma incógnita, mas é notável o fato de o Marquês de Pombal ter recorrido a Ribeiro Sanches quando estava promovendo as reformas pombalinas, ainda que não tenha adotado todas as propostas feitas pelo médico. Nos Apontamentos, de 1763, de Ribeiro Sanches, é possível perceber muitas das ideias adotadas pela Coroa portuguesa em relação ao ensino e à averiguação das potencialidades naturais das colônias, trazendo assim alguns fragmentos de informaçóes dos possíveis conteúdos discutidos por ambos, em cartas.

Nota-se, ainda, que Ribeiro Sanches não somente apresentou o que para ele seriam as atitudes corretas da Coroa em relação à exploração comercial das potencialidades naturais das colônias, como também fez críticas contundentes à Universidade de Coimbra e ao ensino de Medicina, dizendo que:

Aquelle dinheiro que dispende a Universidade de Coimbra com trinta Estudantes de Medicina cada hum com 40 annos, podia empregar-se com maior utilidade do Estado na educação dos Estudantes que proponho, que na daqueles médicos dos quaes não necessita hoje o serviço real. ${ }^{38}$

\footnotetext{
36 BNP, Seção dos reservados, COD. 6941//4, p. 4.

37 PATACA, Ermelinda Moutinho. Terra, água e ar nas viagens cientificas portuguesas (1755-1808), op. cit., p. 30-32.

38 BNP, Seção dos reservados, COD. 6941//4, p. 6-verso.
} 
Esse argumento e a crítica em relaçáo ao ensino em Portugal também podem ser observados em dois textos escritos no mesmo período, que são: Cartas sobre a educação da mocidade, de 1760, e Método para aprender e estudar Medicina, de 1763. O que podemos perceber é a utilização da argumentação já antes proposta por Ribeiro Sanches em ambos os textos citados, mas agora convertidos em um manuscrito cuja finalidade era informar as potencialidades das colônias destinadas à prática da Medicina.

Para isso, Ribeiro Sanches procurou direcionar a discussão no sentido de criticar e incentivar a Coroa a procurar por um maior aproveitamento econômico e científico de seus territórios coloniais, em especial o Brasil. ${ }^{39}$ Para ele, a Coroa deveria considerar as propostas feitas anteriormente em relaçáo à importância do ensino superior e da reforma da Universidade de Coimbra, ressaltando que deveria haver maior intercâmbio dos intelectuais portugueses entre os centros do norte da Europa, evidenciando que a circulaçáo de agentes era de suma importância para a construçáo do conhecimento:

Se uma vez se assentar por cousa certa, que necessita o Estado conhecer as produçóes dos seus domínios, e tirar delas toda a utilidade possível, ninguém duvidará que lhe são necessários homens instruídos, mas ainda na economia dos Estados. Buscará logo o Estado homens dotados destes conhecimentos, e emprega-los na indagação que propomos. Já mandando cinco ou seis estudantes de Medicina de idade de dezoito até vinte anos, dotados de gênio, e engenho, sãos e robustos, capazes de trabalho corporal e de ânimo (o ofício de Boticário e de Naturalista, ou como nós dizemos, de Herbolário, é para caminhar por montes e serras exposto a todos os temporais e a muitos perigos) a aprender a Botânica, e a História Natural em primeiro lugar; e em segundo, aquela Astronomia prática do fazer uma Carta Geográfica, tomar as alturas, marcar as longitudes, conhecimentos necessários no exercício da História Natural nos Climas e nas terras ignoradas, ou pouco conhecidas. ${ }^{40}$

Por se tratar de um texto escrito em 1763, momento em que políticas de Estado marcadas pelos ideais do Marquês de Pombal estavam sendo implementadas, principalmente no que concerne às reformas educacionais, percebemos que a discussão de Ribeiro Sanches, suas críticas e seus apontamentos para as possíveis tomadas de medidas com o objetivo de reconhecimento mais efetivo do Mundo Natural do Brasil se encaixam perfeitamente no contexto do período e iam ao encontro do pensamento de outros intelectuais, como Luis Antonio Verney (1713-1792); João Jacinto de Magalhães (1722-1790); Teodoro de Almeida (1722-1804); Manuel do Cenáculo (1724-1814) e José Monteiro da Rocha (1734-1819). ${ }^{41}$

\footnotetext{
${ }^{39}$ A proposta de Ribeiro Sanches para os Apontamentos, de 1763, era tratar exclusivamente das potencialidades naturais úteis para a Medicina encontradas no Brasil. Entretanto, ao longo do texto, é possível notar que ele também tinha conhecimentos de alguns elementos botânicos africanos.

${ }^{40}$ BNP, Seção dos reservados, COD. 6941//4, p. 6-verso.

${ }^{41}$ CARNEIRO, Ana; SIMÓES, Ana; DIOGO, Maria Paula. Enlightenment science in Portugal, op. cit.
} 
Seu discurso seguia uma linha lógica que procurava demonstrar os benefícios de se conhecer a terra e as possibilidades variadas das produçóes que dela poderiam ser extraídas. Para Ribeiro Sanches, o Rei, por si só, não seria capaz de averiguar, conhecer e trabalhar nessa questão, fazendo-se necessária a formação de um grupo de profissionais com conhecimentos específicos que pudessem desempenhar tal tarefa. Neste excerto, podemos visualizar um discurso que se tornaria unânime entre os intelectuais portugueses, sobretudo a partir dos reinados de D. José I (1750-1777) e D. Maria I (1777-1816):

Mas um Rei ainda que esteja animado daquele animo creador, imitando sempre a Omnibenificencia do Altissimo de quem he imagem na terra, não pode por si só ver tudo, examinar tudo, e ordenar tudo. He necessário usar de Geographos, de Medidores de terras, de homens instruídos na História Natural, na Chimica, na Metallurgia para que depusessem estes conhecimentos adquiridos pelo seo trabalho, no Archivo do Tribunal Economico do Estado, para dalli sair as ordens executivas, que satisfizessem a sua destinação. Se semelhante tribunal estivesse estabelecido no Reino, se as rendas que tem, e que podia ter, fossem fundadas unicamente no trabalho, e na indústria, já os seos domínios de Ultramar, ainda que dilatadíssimas, estariāo examinadas pelo menos na superfície. ${ }^{42}$

Esse ponto fundamental de sua carta, de fato, tornou-se realidade anos depois, com a implementação das Expediçôes Filosóficas para as colônias, então coordenadas por Domingos Vandelli, a partir da Universidade de Coimbra, já reformada. Para Ribeiro Sanches, o ambiente natural colonial deveria ser avaliado para se conhecer o que de melhor poderia ser extraído e cultivado. Conhecer o ambiente natural do Brasil era, para além das questóes estratégicas de demarcação territorial, de comércio e controle, uma maneira de obter o maior número possível de conhecimentos sobre Filosofia Natural e Medicina, principalmente.

Inserido nesse contexto, Ribeiro Sanches apontou inúmeras vantagens acerca do conhecimento sobre História Natural para a economia, agricultura e ciência. Tomando como exemplo a análise de outros países - Inglaterra, Holanda e Espanha - Sanches demonstrou como os referidos países puderam enriquecer seu comércio e sua ciência através de estudos filosófico-naturais de suas possessóes ultramarinas:

Bem me apercebo que me faltam forças, engenho e notícias individuais daquele continente para conseguir tudo o que tenho pensado nesta matéria. Estas dificuldades me determinaram a escrever por tratados separados tudo o que tenho sobre a América. E para tentear as minhas forças, quis neste primeiro, tratar de que modo se deviam buscar os remédios, as especiarias, e outras produçôes, para aumentar as artes mecânicas, que estão já conhecidas pelos Castellanos, Ingleses, e Holandeses, tanto nos seus domínios na América como na Índia Oriental, e na

\footnotetext{
${ }^{42}$ BNP, Seção dos reservados, COD. 6941//4.
} 
África. E também de que modo se podiam descobrir outras muitas produçóes ignoradas até agora na Medicina e no Comércio. ${ }^{43}$

Alguns anos mais tarde, em 1777, o mesmo argumento foi utilizado por Domingos Vandelli em uma carta enviada ao Marquês de Angeja, ${ }^{44}$ em que exaltou o sucesso das Expediçóes Filosóficas realizadas por outros países e a valorização dada por eles aos estudos filosófico-naturais de suas possessóes ultramarinas:

Esta utilidade a tem sentido as mais nações, mandando, nestas e noutras ocasiōes, em companhia de matemáticos, naturalistas inteligentes. Assim o tem praticado a Czarina de Moscóvia, os franceses, ingleses e dinamarqueses, que sabem tirar das ciências naturais todo o proveito que são capazes de produzir. ${ }^{45}$

A preocupação de equivalências em relação aos demais centros europeus se presentificou em boa parte das discussóes e do pensamento filosófico no cenário político e científico português ao longo do século XVIII, principalmente na segunda metade do século, quando se intensificaram as iniciativas para se implementar uma metódica averiguação dos recursos naturais das colônias, baseadas na ideia de uma organizada exploração desses recursos. Ribeiro Sanches manteve esse discurso crítico e comparativo ao longo de todo o texto. Do ponto de vista metodológico, esta estratégia, também usada por outros agentes, como Vandelli, costumava ser útil para que as ideias e propostas pudessem ganhar força e atenção, passando, dessa forma, a circular através de suas redes de contato.

Para Ribeiro Sanches, relativamente às ciências da natureza e ao ensino e à prática da Medicina, deveria haver uma confluência. A Botânica deveria ser uma matéria obrigatória no trabalho de reconhecimento das potencialidades naturais das colônias, e os médicos deveriam ser instruídos sobre os usos e as aplicaçóes das plantas e dos minerais na Medicina. $\mathrm{O}$ que, de fato, foi implementado por Domingos Vandelli quando assumiu as cadeiras de Chymica e de História Natural na Universidade de Coimbra. ${ }^{46}$

Ao longo de toda a segunda metade do século XVIII, podemos notar argumentos muito similares aos de Ribeiro Sanches nos mais variados documentos, escritos por diversos agentes. Por exemplo, em 1792, no texto Memoria sobre a Botânica, e as vantagens, que della rezultâo para a praxe medica, ${ }^{47}$ escrito pelo médico brasileiro Manoel Joaquim de Souza

\footnotetext{
${ }^{43}$ BNP, Seção dos reservados, COD. 6941//4, p. 1.

${ }^{44}$ KURY, Lorelai (org.) Carta de Vandelli ao Marquês de Angeja. In: O gabinete de curiosidades de Domenico Vandelli. Rio de Janeiro: Editora Dantes, 2008.

${ }^{45}$ Domingos Vandelli, 1777. In: KURY, Lorelai (org.) O gabinete de curiosidades de Domenico Vandelli, 2008.

46 PATACA, Ermelinda Moutinho. Terra, água e ar nas viagens cientificas portuguesas (1755-1808), op. cit.

${ }^{47}$ Memoria sobre a Botânica, e as vantagens, que della rezultão para a praxe medica, prezentada á Academia real das sciencias de Lisboa/[por] Manoel Joaquim de Souza Ferraz. - Lisboa, março de 1792. ACL (Academia das Ciências de Lisboa), Série Azul de Manuscritos, COD 375.
} 
Ferraz, ${ }^{48}$ há uma clara crítica à necessidade de o Estado português conhecer melhor as potencialidades naturais do Brasil.

Ferraz ainda disse que somente o Estado poderia incitar nos jovens acadêmicos portugueses o desejo de conhecer as ciências da natureza e a complexidade do ambiente natural de suas colônias. Reforçou a ideia de que somente o Estado poderia "[...] fomentar os progressos da Botanica, permiando aquelles que ahi se aplicação e se distinguem: fornecendo-lhes os meios necessários para viajarem e fazerem descobertas que serão uteis a toda a sociedade [...]" ${ }^{49}$ Lembrou, ainda, que havia muito por ser descoberto em territórios coloniais, e que "[...] só a Portugal pertence a glória de o rasgar; para quando pois difere ele esta importante operação, que toda a republica dos sábios da Europa espera com impaciência? Quanto não seria então aumentada a historia natural e a matéria Medica?". ${ }^{0}$

Notamos que, mesmo com uma diferença de vinte e nove anos entre os textos de Ribeiro Sanches e Ferraz, a preocupação que permeava o ideário dos intelectuais portugueses permanecia relativamente a mesma. A situaçáo político-científica de Portugal e suas colônias, e as mudanças iniciadas em 1750 que culminaram com as políticas implementadas por D. Maria I, incentivavam a intelectualidade portuguesa a escrever sobre temas relacionados com a ciência e o reconhecimento das potencialidades naturais de suas colônias. Tal cenário perdurou até o início do século XIX. As políticas de incentivo à produção de conhecimento e as críticas feitas pela intelectualidade portuguesa, estivesse ela em Portugal ou no estrangeiro, devem ser tomadas como norte para entendermos as preocupaçôes e as necessidades urgentes, relativas à ciência e à circulação de conhecimento pelo Império Português. ${ }^{51}$

\section{Redes de contato e circulação de conhecimento entre Portugal e Brasil}

Salvo os aspectos relativos ao discurso de Ribeiro Sanches sobre a necessidade de implementar políticas mais incisivas para os estudos filosófico-naturais no Brasil, ainda podemos lançar outras vias de análise. É possível, também, analisar toda uma complexa rede de circulação de conhecimentos e agentes que envolveu os Apontamentos, de 1763, e o pensamento de Ribeiro Sanches sobre o Brasil e suas potencialidades naturais, que podem servir de exemplo para o contexto daquele período, que foi, nessa perspectiva, marcado por uma intensa circulação de conhecimentos, baseada, em grande medida, na relação entre ciência e poder. $^{52}$

\footnotetext{
${ }^{48}$ Formado em Medicina em Montpellier e sócio correspondente da Academia das Ciências de Lisboa, Ferraz exerceu Medicina na cidade do Porto por quatro anos, antes de seu regresso ao Brasil, em 1795. Trabalhou em Minas Gerais no vice-reinado do Conde de Resende e, posteriormente, foi para o Rio de Janeiro.

${ }^{49}$ ACL, Série Azul de Manuscritos, COD 375, p. 273.

${ }^{50} \mathrm{Idem}$.

${ }^{51}$ CONCEIÇÃO, Gisele C. Natureza ilustrada, op. cit.

52 Idem.
} 
Como já foi exposto, os agentes produtores de conhecimento científico, ao longo de século XVIII, tinham como via para fazer circular as suas ideias a troca de correspondência entre um extenso número de indivíduos constituintes de uma complexa rede de contatos. ${ }^{53}$ Esse fenômeno de circulação de trabalhos, quantitativamente formado por textos manuscritos, aconteceu em todo o Império Português. Ribeiro Sanches era um agente ativo - escrevia muito e tinha uma vasta rede de contatos - e costumava enviar cartas para indivíduos influentes que pudessem validar o seu conhecimento/pensamento, através da divulgação de seus escritos em diversos círculos de intelectuais e de políticos. Podemos dizer que, para ele, era evidente que se escrevesse para D. Vicente de Sousa Coutinho e para o Marquês de Pombal, poderia ter suas ideias mais facilmente aceitas e assimiladas pela comunidade científica, validando, dessa forma, o seu trabalho. Esse é um cenário onde os jogos de poder estavam inseridos em uma sociedade de corte, na qual a posição social e as relaçóes interpessoais e políticas eram fundamentais para que o trabalho fosse aceito, reconhecido e validado. ${ }^{54}$

As redes de contato de Ribeiro Sanches ultrapassaram os limites da França e Portugal e chegaram até o Brasil através de uma outra carta escrita por ele e endereçada a seu sobrinho que vivia no Brasil - o médico José Henriques Ferreira. ${ }^{55}$ Argumentos coincidentes com os dos Apontamentos, de 1763, podem ser notados nessa carta, que, possivelmente, foi escrita em 1788.

Tal carta foi transcrita e levada a público pelo próprio José Henriques Ferreira, em seu trabalho sobre a Cochonilha, ${ }^{56}$ em 1788. Nesse trabalho, ele afirmou que:

[...] também escreveu para aqui alguns capítulos de huma carta que me escreveu de Paris o Doutor Antonio Ribeiro Sanches em resposta de outra em que eu lhe participava no ano $8^{\mathrm{a}} \mathrm{da}$ Academia; que tinha aqui procurado estabelecer e de outras matérias e produçóes deste País. ${ }^{57}$

Nesse trabalho, o sobrinho de Ribeiro de Sanches, além de tratar das questôes específicas relativas ao cultivo, utilização e comércio da Cochonilha, fez críticas relacionadas à situação da averiguação das potencialidades naturais do Brasil, da transposição e do plantio de espécies de plantas que pudessem ser úteis para a agricultura, e transcreveu um longo trecho da carta

\footnotetext{
53 FURTADO, Júnia Ferreira. Oráculos da Geografia iluminista, op. cit.

${ }^{4}$ BIAGIOLI, Mario. Galileu, cortesão, op. cit.

55 José Henriques Ferreira foi um importante intelectual em território brasileiro. Foi médico do vice-rei Marquês de Lavradio. Acumulou funções como médico do Hospital Real e participou ativamente na fundação da Academia Científica ou Academia de Medicina e História Natural do Rio de Janeiro, em 1772.

${ }^{56}$ Neste período, havia a preocupação com a criação de insetos do gênero Dactylopiuse e a extração da cochonilha, que era, na verdade, a substância que servia como um corante natural. Em boa parte dos trabalhos sobre as potencialidades naturais do Brasil, houve a menção a esse inseto, a sua criação, a extraçáo do corante e a utilidade para o comércio.

${ }^{57}$ Henriques Ferreira. Historia do Descobrimento da Coxonilha no Brazil da sua natureza geração, creação, colheita e utilidades/[por] José Henriques Ferreira, 1788, p. 342. ACL, Série Azul de Manuscritos, COD 374 (30).
} 
enviada pelo tio, em que Ribeiro Sanches deixou transparecer, mais uma vez, suas críticas e ideias para que a Coroa soubesse reconhecer e utilizar os recursos naturais de sua colônia.

Henriques Ferreira transcreveu a parte da carta de Ribeiro Sanches, na qual ele reclamou da falta de droguistas e de uma melhor organização sobre os produtos naturais importantes para a Medicina.

Não há em Lisboa o droguista Real que propus a suma com seu correspondente assalariado para procurar estes produtos naturaes e mandar-los com a sua descrição e para que servem e que usos se faz delles pelos nativos da terra: este mesmo correspondente com ordem de procurar dos naturaes de que remédios uzão para curar as suas queixas, fendas, fraturas, gálicas, cancaros. Sem fazer avanços, e sem gastos jamais haverá nem sciencias, nem artes, nem comercio, nem estado Civil.58

Importa notar que essa transferência de discurso e a circulação de saberes entre Ribeiro Sanches e seu sobrinho ampliam ainda mais a ideia de que o conhecimento produzido, seja na Europa ou nos espaços coloniais, não ficou restrito a um pequeno número de agentes. Os argumentos de Ribeiro Sanches circularam em, pelo menos, três vias distintas: D. Vicente de Sousa Coutinho, o Marquês de Pombal e José Henriques Ferreira. Isso sem contarmos que existe uma possibilidade notável de que D. Luís da Cunha também possa ter tido acesso aos Apontamentos, de 1763. Afinal, a conexão do médico com o embaixador foi próxima e ativa.

Naquele período, a existência de complexas redes de contatos e trocas de correspondência e trabalhos entre os mais variados agentes gerou um extenso volume de textos científicos e críticos a respeito da História Natural do Brasil. As ideias, as críticas e o conhecimento circulavam para além das fronteiras entre a Metrópole e a Colônia. A prova é que Ribeiro Sanches, que nunca voltou a Portugal e tão pouco esteve no Brasil, mencionou no texto de 1763 e voltou a citar na carta enviada ao sobrinho, por exemplo, alguns produtos naturais, suas qualidades e meios de produção, como a Quina, a Ipecacuanha e o óleo de Copaíba, elementos de amplo conhecimento daqueles que exploravam os recursos naturais do Brasil, mas, principalmente, dos médicos e droguistas que utilizavam e comercializam medicamentos vindos dos espaços coloniais. ${ }^{59}$ Esse tipo de informação chegou a ele através de trabalhos escritos por outros agentes, o que demonstra que o conhecimento a respeito do ambiente natural brasileiro circulava de maneira ampla no século XVIII, sobretudo na segunda metade do século.

\footnotetext{
${ }^{58}$ ACL, Série Azul de Manuscritos, COD 374 (30), p. 342.

59 WALKER, Timothy. Acquisition and circulation of medical knowledge within the Portuguese Colonial Empire during the Early Modern period". In: BLEICHMAR, Daniela et al. (eds). Science, power and the order of nature in the Spanish and Portuguese Empires. Stanford University Press, 2009; WALKER, Timothy. The medicines trade in the Portuguese Atlantic world: dissemination of plant remedies and healing knowledge from Brazil, c. 1580-1830. The Social History of Medicine, 26:3, 2013.
} 
A circulação de ideias era fundamental para que a ciência pudesse se desenvolver, se recodificar e formar bases próprias em cada comunidade científica. ${ }^{60}$ No entanto, para isso, as questóes políticas tinham que ser ultrapassadas, e as relaçôes de poder entre os agentes tinham que ser estabelecidas. A simples produção de conhecimento não era suficiente para se fazer validar. O conhecimento tinha que ser aceito e, para isso, as barreiras políticas tinham que ser ultrapassadas. No Império Português, esse processo de circulação de conhecimento, que envolvia os jogos de poder, náo foi menor que em outras localidades. $\mathrm{O}$ que podemos verificar são diferenças marcantes no processo, como, por exemplo, a falta de livros impressos, no entanto, isso não determinou um menor número de trabalhos, nem tão pouco um isolamento ou um menor grau de desenvolvimento científico, mas traduz muito sobre as políticas que envolviam a produção e a divulgação do conhecimento naquele período. A produção científica estava diretamente relacionada com os jogos de poder. A circulação de conhecimento e sua possível validação dependiam do dinamismo das relaçôes interpessoais que cada agente era capaz de formar. ${ }^{61}$

Nesse sentido, vemos que o conhecimento circulava através de redes informais auto-organizadas de agentes, ${ }^{62}$ como no caso daquela formada por Ribeiro Sanches e seus interlocutores. Essas redes faziam com que o conhecimento produzido nos espaços coloniais ganhasse um maior alcance através da circulação desses agentes dentro do complexo do Império Português. Partindo de um local, ampliavam as trocas de informaçôes e conhecimento para uma dimensão mais global, criando, assim, dinâmicas auto-organizadas de produção e circulação de conhecimento. Esse foi o caso de António Nunes Ribeiro Sanches e sua rede de contatos estabelecida a partir de Paris, passando por Portugal e Brasil.

\section{Considerações finais}

Tem se tornado cada vez mais relevante entre os historiadores das ciências a busca por se compreender os processos de circulação de conhecimento através da construção de redes formadas por agentes, de maneira informal e auto-organizada. Neste artigo, procurou-se compreender como tais redes eram constituídas e quais eram os perfis dos agentes envolvidos nas dinâmicas de construção de conhecimento.

\footnotetext{
${ }^{60}$ RAJ, Kapil. Relocating modern science: circulation and the construction of knowledge in South Asia and Europe, 1650-1900. Hampshire, Palgrave Macmillian, 2010; RAJ, Kapil. Beyond postcolonialism... and postpositivism: circulation and the Global History of Science. Isis, v. 104, n. 2, p. 337-347, 2013.

${ }^{61}$ CONCEIÇÃO, Gisele C. Francisco António de Sampaio e sua História Natural da Vila da Cachoeira: circulação, reconfiguração e validação da produção de conhecimento na segunda metade do século XVIII. Revista de História (USP), n. 177, a0022/17, p. 1-35, 2018.

${ }^{62}$ ANTUNES, Cátia e POLÓNIA, Amélia (eds.) Mechanisms of Global Empire building, op. cit.; POLÓNIA, Amélia e ANTUNES, Cátia. Seaports in the First Global Age, op. cit.
} 
O que podemos notar, a partir das análises desenvolvidas neste artigo, é que, no século XVIII, apesar de, em relação ao volume de manuscritos, ser notoriamente pequeno o número de trabalhos a circular impressos, não se pode dizer que isso gerou um aprisionamento de ideias dentro de espaços confinados ou apenas dentro do Império Português. O conhecimento científico, sobre os mais variados temas, circulava e era validado através de trocas de correspondência, tanto na Colônia, em Portugal, ou em outras localidades fora do Império. Como havia muitos agentes, diplomatas, médicos e outros intelectuais, inseridos nas colônias e nos centros do norte da Europa, o conhecimento circulava e se difundia através desta complexa rede auto-organizada, que envolvia muitos territórios e uma grande diversidade de indivíduos.

Foi devido ao expressivo envolvimento do Estado e das instituiçôes científicas em iniciativas para se reconhecer as potencialidades naturais das colônias que um grande número de indivíduos, com variadas formaçôes e atuaçôes profissionais, figurou no centro dos processos de construção de conhecimentos sobre o ambiente natural brasileiro. É possível considerá-la como uma marca do modelo de produçáo de conhecimento dentro do Império Português, que acabou por imprimir características bastante distintas ao ambiente científico e aos trabalhos sobre o Mundo Natural colonial, formando uma tipologia de trabalhos muito variada, mas que compartilhava o mesmo objetivo - conhecer e saber explorar a natureza dos territórios coloniais.

A circulação desses indivíduos no ambiente científico europeu e colonial, assim como de suas ideias e seus textos, nos abre uma via de análise para a compreensão de como o conhecimento científico era produzido, assimilado e reconfigurado de acordo com as especificidades de cada localidade. ${ }^{63}$ Isso não implica que a análise se torne regional, mas sim, na tentativa de desprender-se da ideia de que só havia construção de conhecimento científico nos grandes centros. Se fecharmos o cerne da discussão no ambiente europeu ou no colonial, excluímos algumas possibilidades de análise e deixamos de lado algumas características singulares do processo de construção do conhecimento científico.

No caso de Portugal e do Brasil, isso é evidente. Primeiro, porque a circulação do conhecimento não se dava apenas entre o Reino e a Colônia, mas sim em um universo mais amplo, que envolvia muitos agentes e territórios. Se pensarmos no processo como sendo circulatório e não unidirecional, podemos perceber que o conhecimento se difundia de maneira muito mais complexa e que seus processos de construçấo de conhecimento se davam em vários momentos, em diversos territórios e pelas mãos dos mais variados agentes produtores.

\footnotetext{
${ }^{63}$ RAJ, Kapil. Beyond postcolonialism... and postpositivism, op. cit.; RAJ, Kapil. Relocating Modern Science, op. cit:; LIVINGSTONE, David N. Putting science in its place, op. cit.
} 


\section{Fontes}

Henriques Ferreira. Historia do Descobrimento da Coxonilha no Brazil da sua natureza geração, creação, colheita e utilidades/[por] José Henriques Ferreira, 1788, p. 342. ACL, Série Azul de Manuscritos, COD 374 (30).

Memoria sobre a Botânica, e as vantagens, que della rezultáo para a praxe medica, prezentada á Academia real das sciencias de Lisboa/[por] Manoel Joaquim de Souza Ferraz - Lisboa, março de 1792. ACL (Academia das Ciências de Lisboa), Série Azul de Manuscritos, COD 375. Biblioteca Nacional de Portugal (BNP), Lisboa: Seção dos Reservados, COD. 6941//4.

\section{Referências}

ABREU, Laurinda. Public health and social reforms in Portugal (1780-1805). New Castle, Cambridge Scholars Publishing, 2017.

ABREU, Jean Luiz Neves. Higiene e conservação da saúde no pensamento médico lusobrasileiro do século XVIII. Asclepio (Madrid), v. 62, p. 225-250, 2010.

ALENCASTRO, Luiz Felipe de. A rede económica do Mundo Atlântico português. In: BETHENCOURT, Francisco; CURTO, Diogo Ramada. A expansão marítima portuguesa, 1400-1800. Lisboa: Ediçóes 70, 2010.

BIAGIOLI, Mario. Galileu, cortesão. A prática da ciência na cultura do Absolutismo. Coordenação da coleção: Ana Simões e Henrique Leitão. Porto: Porto Editora, 2003.

BRIGOLA, João Carlos. Coleç̧ôes, gabinetes e museus em Portugal no século XVIII. Lisboa: Fundação Calouste Gulbenkian, 2003.

CAROLINO, Luis Miguel. State, science and empire in the Portuguese Atlantic (1770s-1820s). The Portuguese Journal of Social Science, [S.1.], v. 16, n. 1, sep. 2017.

CARNEIRO, Ana; SIMÓES, Ana; DIOGO, Maria Paula. Enlightenment science in Portugal: The estrangeirados and their communication networks. Social Studies of Science 30/4, p. 591-619, 2000.

CARVALHO, Rómulo de. A História Natural em Portugal no século XVIII. Lisboa: Instituto de Cultura e Língua Portuguesa, 1987.

CONCEIÇÃO, Gisele C. Francisco António de Sampaio e sua História Natural da Vila da Cachoeira: circulação, reconfiguração e validação da produção de conhecimento na segunda metade do século XVIII. Revista de História (USP), n. 177, a0022/17, p. 1-35, 2018.

CONCEIÇÃO, Gisele C. Science and power relations: circulation of agents and knowledge between Portugal and Brazil in the eighteenth century. In: POLÓNIA, Amélia; BRACHT, 
Fabiano; CONCEIÇÃO, Gisele C.; PALMA, Monique (orgs.). Cross-cultural exchange and the circulation of knowledge in the First Global Age. 1. ed. Porto: Ediçóes Afrontamento/ CITCEM, 2018, v. 1, p. 15-35.

CONCEIÇÃO, Gisele C. Natureza ilustrada. Processos de construção de conhecimento filosófico-natural sobre o Brasil na segunda metade do século XVIII. Tese (Doutorado). Faculdade de Letras da Universidade do Porto, 2017a.

CONCEIÇÃO, Gisele C. Evidências da circulação de conhecimento filosófico-natural sobre o Brasil em um manuscrito de 1763 de António Nunes Ribeiro Sanches. História, Ciências, Saúde-Manguinhos, Rio de Janeiro, v. 24, p. 519-533, 2017.

CONCEIÇÃO, Gisele C. Natureza ilustrada: estudos sobre Filosofia Natural no Brasil ao longo século XVIII. In: POLÓNIA, Amélia; BRACHT, Fabiano; CONCEIÇÃO, Gisele C.; PALMA, Monique (orgs.). História e ciência: ciência e poder na Primeira Idade Global. 1. ed. Porto: Universidade do Porto. Faculdade de Letras, v. 1, p. 142-179, 2016.

DENIPOTI, Cláudio; LIMA E FONSECA, Thais Nivea de. Censura e mercê - os pedidos de leitura e posse de livros proibidos em Portugal no século XVIII. Revista Brasileira de História da Ciência, Rio de Janeiro, v. 4, n. 2, p. 139-154, 2011.

DOMINGUES, Ângela. Oficiais, cavalheiros e concorrentes: o "Brasil” nas viagens de circumnavegação do século das Luzes. Revista de Indias. v. LXXIII, n. 258, p. 365-398, 2013.

DOMINGUES, Ângela. Para um melhor conhecimento dos domínios coloniais: a constituição de redes de informação no Império Português em finais do setecentos. História, Ciências, Saúde-Manguinhos, v. VIII (suplemento), p. 823-838, 2001.

FURTADO, Júnia Ferreira. Oráculos da Geografia iluminista: Dom Luís da Cunha e JeanBaptiste Bourguignon D’Anville na construção da cartografia do Brasil. Belo Horizonte: UFMG, 2012.

GRANT, Edward. Os fundamentos da Ciência Moderna na Idade Média. Porto: Porto Editora, 2002.

KURY, Lorelai. O naturalista Veloso. Revista História (USP). São Paulo, n. 172, p. 243-277, jan./jun. 2015.

KURY, Lorelai. Carta de Vandelli ao Marquês de Angeja. In: O gabinete de curiosidades de Domenico Vandelli. Rio de Janeiro: Editora Dantes, 2008.

LEMOS, Maximiano. Ribeiro Sanches: a sua vida e a sua obra. Porto: Eduardo Tavares Martins, 1911.

LIVINGSTONE, David N. Putting science in its place: geographies of science knowledge. Chicago: University of Chicago Press, 2013.

PATACA, Ermelinda Moutinho. Terra, água e ar nas viagens cientificas portuguesas (17551808). Tese (Doutorado) Universidade Estadual de Campinas, Instituto de Geociências, Campinas, 2006. 
POLÓNIA, Amélia; ANTUNES, Cátia. Mechanisms of Global Empire building. Oporto: CITCEM, 2017.

POLÓNIA, Amélia; ANTUNES, Cátia. Seaports in the First Global Age: Portuguese agents, networks and interactions (1500-1800). Oporto: UPorto Editora, 2017a.

PAQUETTE, Gabriel. Political economy, local knowledge, and the reform of the Portuguese Empire, c. 1750-1810. In: ASTIGARRAGA, Jesús; USOZ, Javier (eds.). L'économie politique et la sphère publique dans le débat des Lumières. Madrid: Casa de Velázquez, p. 245-258, 2013. RAJ, Kapil. Relocating Modern Science: circulation and the construction of knowledge in South Asia and Europe, 1650-1900. Hampshire, Palgrave Macmillian, 2010.

RAJ, Kapil. Beyond postcolonialism... and postpositivism: circulation and the Global History of Science. Isis, v. 104, n. 2, p. 337-347, 2013.

RAMINELLI, Ronald. Viagens ultramarinas. Monarcas, vassalos e governo a distância. São Paulo: Alameda, 2008.

RAMOS-JUNIOR, Nelson de Campos. Mediador das Luzes: concepçôes de progresso e ciência em António Nunes Ribeiro Sanches (1699-1783). Dissertação (Mestrado), Faculdade de Filosofia, Letras e Ciências Humanas, Universidade de São Paulo, São Paulo, 2013.

SÁ, Victor de. Ribeiro Sanches: "Dificuldades que tem um Reino velho para emendar-se" e outros textos/seleção, apresentação e notas de Victor de Sá. 2 ed. Lisboa: Livros Horizonte, 1980. p. 146.

SANJAD, Nelson. Ciência e poder imperial no Grão-Pará: da expansão à desconstrução (1750-1840). In: KURY, Lorelai; GESTEIRA, Heloisa (orgs.). Ensaios de história das ciências no Brasil: das Luzes à nação independente. Rio de Janeiro: EdUERJ, 2012.

SILVA, Innocencio Francisco da. Diccionario Bibliographico Portuguez - Estudos de Innocencio Francisco da Silva Applicaveis a Portugal e ao Brasil. Tomo VIII (1º suplemento), Lisboa, na Imprensa Nacional, 1867.

VANDELLI, Domingos. Carta de Vandelli ao Marquês de Angeja (1777). In: Kury, Lorelai (org.). O gabinete de curiosidades de Domenico Vandelli. Rio de Janeiro: Dantes Livraria, 2008. VOGEL, Christine. Guerra aos jesuitas. A propaganda antijesuítica do Marquês de Pombal em Portugal e na Europa. Lisboa: Temas e Debates - Círculo de Leitores, 2017.

WALKER, Timothy. Acquisition and circulation of medical knowledge within the Portuguese Colonial Empire during the Early Modern Period. In: BLEICHMAR, Daniela et al. (eds.). Science, power and the order of nature in the Spanish and Portuguese Empires. Stanford University Press, 2009.

WALKER, Timothy. The medicines trade in the Portuguese Atlantic World: dissemination of plant remedies and healing knowledge from Brazil, c. 1580-1830. The Social History of Medicine, 26:3, 2013. 